\title{
Xilanases: Principais Metodologias e Parâmetros Cinéticos
}

Review

\author{
Leandro Freire dos Santos $^{1 *}$ e Priscila Lumi Ishii ${ }^{2}$ \\ ${ }^{1}$ Departamento de Engenharia de Bioprocessos e Biotecnologia; Universidade Federal do Paraná; 81531-970; \\ Curitiba - PR - Brasil. ${ }^{2}$ Departamento de Biologia Celular e Molecular; Universidade Estadual Paulista Júlio de \\ Mesquita Filho; 13506-900; São Paulo - SP - Brasil.
}

\begin{abstract}
Endo-1,4- $\beta$-xylanases are extracellular enzymes that make the hydrolysis of substrates $\beta$ 1,4. Xylan is the main representative among the substrates that are susceptible to hydrolytic attack of xylanases. Xylanases have a wide application in different sectors of the economy. The purpose of this study was to review the published literature on the main methodologies used to study these enzymes, as well as gather some kinetic parameters. The reviewed methodologies are centered mainly in the purification process, since that is an essential step for the optimization of its enzymatic activity and therefore industrial application. The highlights are the techniques that use the saline precipitation and refined methodologies as chromatography and its variations, as well as factorial design studies and enzyme immobilization. These methodologies aim respectively, among other things, optimal conditions for enzyme production and recycling.
\end{abstract}

Key words: Enzymatic activity, purification techniques, immobilization of enzymes, xylan, thermostability

\section{INTRODUÇÃO}

As endo $\beta$ 1,4 xilanases (EC 3.2.1.8) são enzimas extracelulares, produzidas principalmente por bactérias e fungos, que fazem a hidrólise das ligações $\beta 1,4$ na xilana principalmente. A xilana é composta por resíduos de $\beta$-xilopiranose, unidos por ligações $\beta 1,4$, com graus variáveis de substituições em suas cadeias laterais. Os produtos da hidrólise das xilanases são constituídos de monômeros D-xilose e xilo-oligossacarídeos de diferentes tamanhos. (Heck, 2006; Jänis, 2007).

As xilanases apresentam amplo emprego industrial. Pesquisas recentes exploram sua aplicabilidade no setor alimentício e processamento do papel (Haros et al., 2002; Jiang et al., 2008; Bae et al., 2008). Sendo assim, é de grande importância estudos que objetivam obter maiores rendimentos na produção das xilanases. Obter altos rendimentos na produção da enzima é desejável no âmbito industrial. Otimizações no rendimento podem ser conseguidas através de planejamentos fatoriais de certas variáveis importantes para a produção. Fontes de nitrogênio, carbono, tempo e temperatura de cultivo, dentre outros, são variáveis importantes para serem estudados ( $\mathrm{Li}$ et al., 2007). Além disso, otimizações no rendimento também podem ser obtidos por processos apurados de purificação (Zuniga et al., 2003). A atividade enzimática sempre deve ser verificada, após um processo de purificação, para visualização de uma possível aplicação industrial (Decelle et al., 2004; Sapre et al., 2005; Kolenová et al., 2005).

$\mathrm{O}$ objetivo deste trabalho foi expor metodologias usadas para se trabalhar com xilanases e reunir alguns parâmetros cinéticos. Tais informações podem ser necessárias para otimizações do rendimento e ampliação da sua aplicabilidade industrial.

\section{MATERIAL E MÉTODOS \\ Metodologias utilizadas para se trabalhar com xilanases}

A Tabela 1 mostra dados acerca dos microrganismos produtores de xilanases, especificando os substratos utilizados, condições de $\mathrm{pH}$, temperatura e principais técnicas de purificação dos trabalhos revisados. 
Tabela 1. Microrganismos produtores de xilanases (*)

\begin{tabular}{|c|c|c|c|c|}
\hline $\begin{array}{l}\text { Microrganismos } \\
\text { Produtores }\end{array}$ & Substratos Utilizados & $\begin{array}{l}\text { Condições de } \\
\text { Cultivo (pH e } \\
\text { temperatura) }\end{array}$ & $\begin{array}{l}\text { Técnicas de } \\
\text { Purificação }\end{array}$ & Autor(es) \\
\hline $\begin{array}{l}\text { Caldibacillus } \\
\text { cellulovorans }\end{array}$ & Xilana & $\mathrm{pH} 6,0 ; 70$ e $90^{\circ} \mathrm{C}$ & $\begin{array}{l}\text { Cromatografia de } \\
\text { troca aniônica }\end{array}$ & $\begin{array}{l}\text { Sunna et al., } \\
2000\end{array}$ \\
\hline $\begin{array}{l}\text { Acrophialophora } \\
\text { nainiana }\end{array}$ & Xilana & $\mathrm{pH} 7,0 ; 55^{\circ} \mathrm{C}$ & $\begin{array}{l}\text { Cromatografia } \\
\text { troca iônica } \\
\text { filtração a gel }\end{array}$ & $\begin{array}{l}\text { Salles et al., } \\
2000\end{array}$ \\
\hline Streptomyces SP. & $\begin{array}{l}\text { Xilana; 4-nitrofenol beta- } \\
\text { D-xilopiranosídeo; } \\
\text { nitrofenol celobiosídico; 4- } \\
\text { nitrofenol } \\
\text { arabinofuranosídico }\end{array}$ & $\mathrm{pH} 6,0 ; 60^{\circ} \mathrm{C}$ & $\begin{array}{lr}\text { Cromatografia } & \text { de } \\
\text { troca iônica } & \text { e } \\
\text { filtração a gel } & \end{array}$ & $\begin{array}{l}\text { Georis et al., } \\
2000\end{array}$ \\
\hline Euphausia superba & $\begin{array}{l}\text { Xilana; 4-nitrofenol beta- } \\
\text { D-xilopiranosídeo }\end{array}$ & $\begin{array}{l}\mathrm{pH} \\
40^{\circ} \mathrm{C}\end{array}$ & $\begin{array}{l}\text { Cromatrografia de } \\
\text { troca iônica }\end{array}$ & $\begin{array}{l}\text { Turkiewicz et } \\
\text { al., } 2000\end{array}$ \\
\hline Lentinus edodes & Xilana & $\begin{array}{l}\mathrm{pH} \quad 4,0 \quad \mathrm{e} \quad 5,0 ; \\
50,60,90{ }^{\circ} \mathrm{C}\end{array}$ & $\begin{array}{l}\text { Cromatografia } \\
\text { troca iônica } \\
\text { filtração a gel }\end{array}$ & $\begin{array}{l}\text { Ramos et al., } \\
2000\end{array}$ \\
\hline Bacillus sp. & Xilana & $\mathrm{pH} 6,0-7,0 ; 70^{\circ} \mathrm{C}$ & $\begin{array}{l}\text { Precipitação com } \\
\text { sulfato de amônio e } \\
\text { cromatografia de } \\
\text { troca iônica }\end{array}$ & $\begin{array}{l}\text { Takahashi et } \\
\text { al., } 2000\end{array}$ \\
\hline $\begin{array}{l}\text { Melanocarpus } \\
\text { albomyces }\end{array}$ & $\begin{array}{l}\text { Xilana; 4-nitrofenol beta- } \\
\text { D-xilopiranosídeo }\end{array}$ & $\begin{array}{l}\text { Variável conforme } \\
\text { isozima }\end{array}$ & $\begin{array}{l}\text { Cromatografia } \\
\text { troca iônica } \\
\text { filtração a gel }\end{array}$ & $\begin{array}{l}\text { Saraswat \& } \\
\text { Bisaria, 2000 }\end{array}$ \\
\hline $\begin{array}{l}\text { Streptomyces } \\
\text { olivaceoviridis }\end{array}$ & 1,4-beta-D-xilana & $\mathrm{pH} 6,0 ; 60^{\circ} \mathrm{C}$ & $\begin{array}{lr}\text { Cromatografia } & \text { de } \\
\text { troca iônica } & \text { e } \\
\text { filtração a gel } & \end{array}$ & $\begin{array}{l}\text { Kaneko et al., } \\
2000\end{array}$ \\
\hline Bacillus sp. & $\begin{array}{l}\text { Arabinoxilano; 1,4-beta-D- } \\
\text { xilana }\end{array}$ & $\mathrm{pH} 6,0-7,0 ; 75^{\circ} \mathrm{C}$ & $\begin{array}{l}\text { Precipitação com } \\
\text { sulfato de amônio, } \\
\text { cromatografia de } \\
\text { troca aniônica e } \\
\text { filtração a gel }\end{array}$ & $\begin{array}{l}\text { Bataillon } \\
\text { al., } 2000\end{array}$ \\
\hline Staphylococcus sp. & 1,4-beta-D-xilana & $\begin{array}{l}\mathrm{pH} 7,5 \text { e } 9,2 ; \text { nd } \\
(*)\end{array}$ & $\begin{array}{l}\text { Precipitação com } \\
\text { sulfato de amônio, } \\
\text { cromatografia de } \\
\text { troca aniônica e } \\
\text { filtração a gel }\end{array}$ & $\begin{array}{l}\text { Gupta et al., } \\
2000\end{array}$ \\
\hline $\begin{array}{l}\text { Thermoascus } \\
\text { aurantiacus }\end{array}$ & $\begin{array}{l}\text { Xilotrioses, xilotetroses, } \\
\text { xilopentoses, xilohexoses, } \\
\text { arabinoxilana, } \\
\text { glucuronoxilana }\end{array}$ & $\mathrm{pH} 5,0 ; 50^{\circ} \mathrm{C}$ & Filtração a gel & $\begin{array}{l}\text { Kalogeris et } \\
\text { al.,2001 }\end{array}$ \\
\hline Thermomonospora sp. & Xilana & $\mathrm{Nd} ; 80^{\circ} \mathrm{C}$ & $\begin{array}{l}\text { Precipitação com } \\
\text { sulfato de amônio, } \\
\text { cromatografia de } \\
\text { troca iônica e } \\
\text { filtração a gel }\end{array}$ & $\begin{array}{l}\text { George et al., } \\
2000\end{array}$ \\
\hline Phelbia radiata & Xilana & nd & $\begin{array}{l}\text { Cromatografia de } \\
\text { troca iônica }\end{array}$ & $\begin{array}{l}\text { Rogalski et al., } \\
2001\end{array}$ \\
\hline Fusarium proliferatum & Xilana & $\mathrm{pH} 5,0-5,5 ; 55^{\circ} \mathrm{C}$ & $\begin{array}{l}\text { Precipitação com } \\
\text { sulfato de amônio e }\end{array}$ & Saha, 2002 \\
\hline
\end{tabular}




\begin{tabular}{|c|c|c|c|c|}
\hline $\begin{array}{l}\text { Pseudoalteromonas } \\
\text { haloplanktis }\end{array}$ & $\begin{array}{l}\text { Xilana } \\
\text { xilooligossacarídeos }\end{array}$ & $\begin{array}{l}\mathrm{pH} 5,3-8,0\left(25^{\circ} \mathrm{C}\right) \\
25^{\circ} \mathrm{C}\end{array}$ & $\begin{array}{l}\text { cromatografia } \\
\text { Ultrafiltração } \\
\text { cromatografia de } \\
\text { troca iônica }\end{array}$ & Collins, 2002 \\
\hline $\begin{array}{l}\text { Thermomyces } \\
\text { lanuginosus }\end{array}$ & $\begin{array}{l}\text { Xilana e 4-O-metil- } \\
\text { glucuronoxilana }\end{array}$ & $\mathrm{pH} 7,0 ; 60^{\circ} \mathrm{C}$ & $\begin{array}{l}\text { Cromatografia de } \\
\text { troca aniônica } \mathrm{e} \\
\text { filtração a gel }\end{array}$ & $\begin{array}{l}\text { Bakalova } \\
\text { al., } 2002\end{array}$ \\
\hline $\begin{array}{l}\text { Acrophialophora } \\
\text { nainiana }\end{array}$ & Xilana & $\mathrm{pH} 6,5 ; 55-65^{\circ} \mathrm{C}$ & $\begin{array}{l}\text { Ultrafiltração, } \\
\text { cromatografia de } \\
\text { troca iônica e } \\
\text { filtração a gel }\end{array}$ & $\begin{array}{l}\text { Cardoso \& } \\
\text { Ferreira, } 2003\end{array}$ \\
\hline Cellulomonas flavigena & Xilana & $\mathrm{pH} 6,5 ; 50-55^{\circ} \mathrm{C}$ & Filtração a gel & $\begin{array}{l}\text { Martinez- } \\
\text { Trujillo et al., } \\
2003\end{array}$ \\
\hline $\begin{array}{l}\text { Sporotrichum } \\
\text { thermophile }\end{array}$ & $\begin{array}{l}\text { Derivados da } \\
\text { xilotriose } \\
\text { glucuronoxilana }\end{array}$ & $\mathrm{pH} 5,0 ; 70^{\circ} \mathrm{C}$ & $\begin{array}{l}\text { Cromatografia de } \\
\text { troca iônica } \\
\text { filtração a gel }\end{array}$ & $\begin{array}{l}\text { Katapodis et } \\
\text { al., } 2003\end{array}$ \\
\hline $\begin{array}{l}\text { Thermomyces } \\
\text { lanuginosus }\end{array}$ & Xilana & $\mathrm{pH} 6,0 ; 75^{\circ} \mathrm{C}$ & Filtração a gel & $\begin{array}{l}\text { Damoso et al., } \\
2003\end{array}$ \\
\hline Streptomyces sp. K37 & Xilana e arabinogalactana & $\mathrm{pH} 6,0 ; 60^{\circ} \mathrm{C}$ & $\begin{array}{l}\text { Cromatografia de } \\
\text { troca catiônica e } \\
\text { filtração a gel }\end{array}$ & $\begin{array}{l}\text { Mansour et al., } \\
2003 .\end{array}$ \\
\hline $\begin{array}{l}\text { Phanerochaete } \\
\text { chrysosporium }\end{array}$ & $\begin{array}{l}\text { Xilana, p-nitrofenol beta- } \\
\text { D-xilopiranosídico e p- } \\
\text { nitrofenol beta-D- } \\
\text { celobiosídico }\end{array}$ & $\begin{array}{l}\mathrm{pH} 4,5 ; 60 \text { (iso*. B) } \\
\text { e } 70^{\circ} \mathrm{C} \text { (iso.A,C) }\end{array}$ & $\begin{array}{lr}\text { Precipitação por } \\
\text { sulfato de amônio, } \\
\text { diálise, } \\
\text { cromatografia } \\
\text { afinidade } \\
\text { cromatografia } \\
\text { troca iônica }\end{array}$ & $\begin{array}{l}\text { Decelle et al., } \\
2004\end{array}$ \\
\hline $\begin{array}{l}\text { Bacillus } \\
\text { thermantarcticus }\end{array}$ & Xilana & $\mathrm{pH} 5,6 ; 80^{\circ} \mathrm{C}$ & Filtração a gel & $\begin{array}{l}\text { Lama et al., } \\
2004\end{array}$ \\
\hline Thermotoga maritima & $\begin{array}{l}\text { Xilana } \\
\text { xilooligossacarídeos }\end{array}$ & $\mathrm{pH} 6,1 ; 50^{\circ} \mathrm{C}$ & $\begin{array}{l}\text { Enzima } \\
\text { recombinante, } \\
\text { Cromatografia por } \\
\text { afinidade }\end{array}$ & $\begin{array}{l}\text { Jiang et al., } \\
2004\end{array}$ \\
\hline $\begin{array}{l}\text { Pseudobutyrivibrio } \\
\text { xylanivorans }\end{array}$ & Xilana & $\mathrm{pH} 5,6 ; 38^{\circ} \mathrm{C}$ & $\begin{array}{l}\text { Precipitação por } \\
\text { sulfato de amônio e } \\
\text { cromatografia por } \\
\text { interação } \\
\text { hidrofóbica }\end{array}$ & $\begin{array}{l}\text { Cepeljnik et } \\
\text { al., } 2004\end{array}$ \\
\hline Bacillus sp. & Xilana & $\begin{array}{l}\mathrm{pH} \\
50^{\circ} \mathrm{C}\end{array}$ & $\begin{array}{l}\text { Precipitação por } \\
\text { sulfato de amônio, } \\
\text { diálise, } \\
\text { cromatografia de }\end{array}$ & $\begin{array}{l}\text { Sapre et al., } \\
2005\end{array}$ \\
\hline Aspergillus versicolor & Xilana & $\mathrm{pH} 6,0-7,0 ; 55^{\circ} \mathrm{C}$ & $\begin{array}{l}\text { troca iônica e } \\
\text { filtração a gel } \\
\text { Diálise, } \\
\text { cromatografia de } \\
\text { troca iônica, } \\
\text { osmose reversa }\end{array}$ & $\begin{array}{l}\text { Carmona et al., } \\
2005\end{array}$ \\
\hline Aspergillus caespitosus & Xilana e polpa kraft & $\begin{array}{l}\text { pH 5,5-6,5 (iso.II); } \\
6,5-7,0 \text { (iso.I); 50- }\end{array}$ & Filtração a gel & $\begin{array}{l}\text { Sandrim et al., } \\
2005\end{array}$ \\
\hline
\end{tabular}




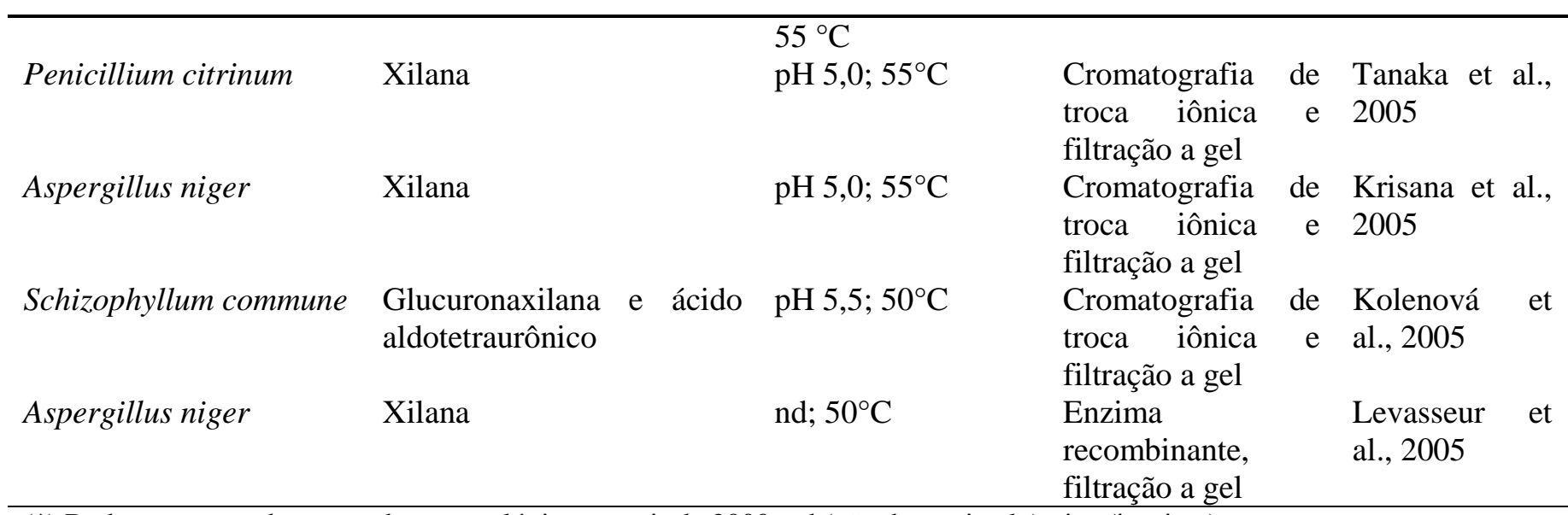

(*) Dados apresentados em ordem cronológica a partir de 2000; nd (não determinado); iso (isozima)

A Tabela 2 aborda referências revisadas acerca das constantes michaelanas $(\mathrm{Km})$ e substratos utilizados. Tal compilação promove uma visão global das últimas pesquisas e resultados acerca de potenciais microrganismos produtores e substratos indutores.

Tabela 2. Valores das constantes de Michaelis Menten (Km)

\begin{tabular}{|c|c|c|c|c|}
\hline $\mathrm{Km}\left(\mathrm{mg} \cdot \mathrm{ml}^{-1}\right)$ & Comentário & Substrato & Microrganismo* & $\overline{\text { Autor(es) }}$ \\
\hline 40,9 & $\mathrm{Km}$ aparente; $50^{\circ} \mathrm{C}$ & Xilana solúvel & $\begin{array}{l}\text { Acrophialophora } \\
\text { nainiana }\end{array}$ & $\begin{array}{l}\text { Salles et al., } \\
2000\end{array}$ \\
\hline 16,1 & $\mathrm{Km}$ aparente; $50^{\circ} \mathrm{C}$ & Xilana insolúvel & $\begin{array}{l}\text { Acrophialophora } \\
\text { nainiana }\end{array}$ & $\begin{array}{l}\text { Salles et al., } \\
2000\end{array}$ \\
\hline 0,97 & $56^{\circ} \mathrm{C} ; \mathrm{pH} 6,0$ & Xilana & Aspergillus nidulans & $\begin{array}{l}\text { Fernández- } \\
\text { Espinar et al., } \\
1994\end{array}$ \\
\hline 0,7 & $60^{\circ} \mathrm{C} ; \mathrm{pH} 6,0$ & Xilana & Bacillus sp. & $\begin{array}{l}\text { Bataillon et al., } \\
2000\end{array}$ \\
\hline 1,0 & $\begin{array}{l}\text { Enzima } \\
\text { recombinante, }\end{array}$ & Xilana (birchwood) & $\begin{array}{l}\text { Caldibacillus } \\
\text { cellulovorans }\end{array}$ & $\begin{array}{l}\text { Sunna et al., } \\
2000 .\end{array}$ \\
\hline 1,$72 ; 1,68 ; 1,25$ & $\begin{array}{l}\text { Xilanase } \mathrm{A}, \mathrm{B} \text { e } \mathrm{C} \\
\text { respectivamente }\end{array}$ & $\begin{array}{l}\text { Carboximetilcelulose e } \\
\text { Xilana }\end{array}$ & Cellulomonas fimi & $\begin{array}{l}\text { Khanna e Gauri, } \\
1993\end{array}$ \\
\hline 1,27 & $50-55^{\circ} \mathrm{C}$ & Xilana (Birchwood) & $\begin{array}{l}\text { Cellulomonas } \\
\text { flavigena }\end{array}$ & $\begin{array}{l}\text { Martinez- } \\
\text { Trujillo et al., } \\
2003\end{array}$ \\
\hline 0,65 & $60^{\circ} \mathrm{C} ; \mathrm{pH} 5,8$ & Xilana (larchwood) & $\begin{array}{l}\text { Clostridium } \\
\text { thermolacticum }\end{array}$ & $\begin{array}{l}\text { Debeire } \\
\text { al.,1990 }\end{array}$ \\
\hline 4,$1 ; 7,7$ & $\begin{array}{l}\text { Endo-1,4-beta- } \\
\text { xilanase A e B } \\
\text { respectivamente }\end{array}$ & Xilana de aveia & Euphausia superba & $\begin{array}{l}\text { Turkiewicz } \\
\text { al., } 2000 .\end{array}$ \\
\hline 1,63 & $55^{\circ} \mathrm{C}$ & Xilana & $\begin{array}{l}\text { Geobacillus } \\
\text { stearothermophilus }\end{array}$ & $\begin{array}{l}\text { Khasin } \\
\text { al.,1990 }\end{array}$ \\
\hline 2,$14 ; 2,07 ; 0,4$ & $\begin{array}{ll}\mathrm{Ia}, \quad \mathrm{Ib}, & \mathrm{Ic} \\
\text { respectivamente } & \end{array}$ & Xilana (Larchwood) & $\begin{array}{l}\text { Melanocarpus } \\
\text { albomyces }\end{array}$ & $\begin{array}{l}\text { Saraswat \& } \\
\text { Bisaria, 2000 }\end{array}$ \\
\hline 5,$56 ; 4,97 ; 6,90 ; 2,31$ & $\begin{array}{l}\text { IIa, IIb, IIc, IId } \\
\text { respectivamente }\end{array}$ & $\begin{array}{l}\text { Xilana (Birchwood a,c; } \\
\text { Beechwood b,d) }\end{array}$ & $\begin{array}{l}\text { Melanocarpus } \\
\text { albomyces }\end{array}$ & $\begin{array}{l}\text { Saraswat \& } \\
\text { Bisaria, 2000 }\end{array}$ \\
\hline 4,$86 ; 2,7$ & $\begin{array}{l}\text { XA-1 e } \text { XA-2 } \\
\text { respectivamente }\end{array}$ & Xilana (Larchwood) & Phelbia radiata & $\begin{array}{l}\text { Rogalski et al., } \\
2001\end{array}$ \\
\hline $0,5-5,0$ & $\begin{array}{l}\text { Km aparente; família } \\
8 \text { das xilanases, }\end{array}$ & Xilana & $\begin{array}{l}\text { Pseudoalteromonas } \\
\text { haloplanktis }\end{array}$ & $\begin{array}{l}\text { Collins et al., } \\
2002\end{array}$ \\
\hline
\end{tabular}




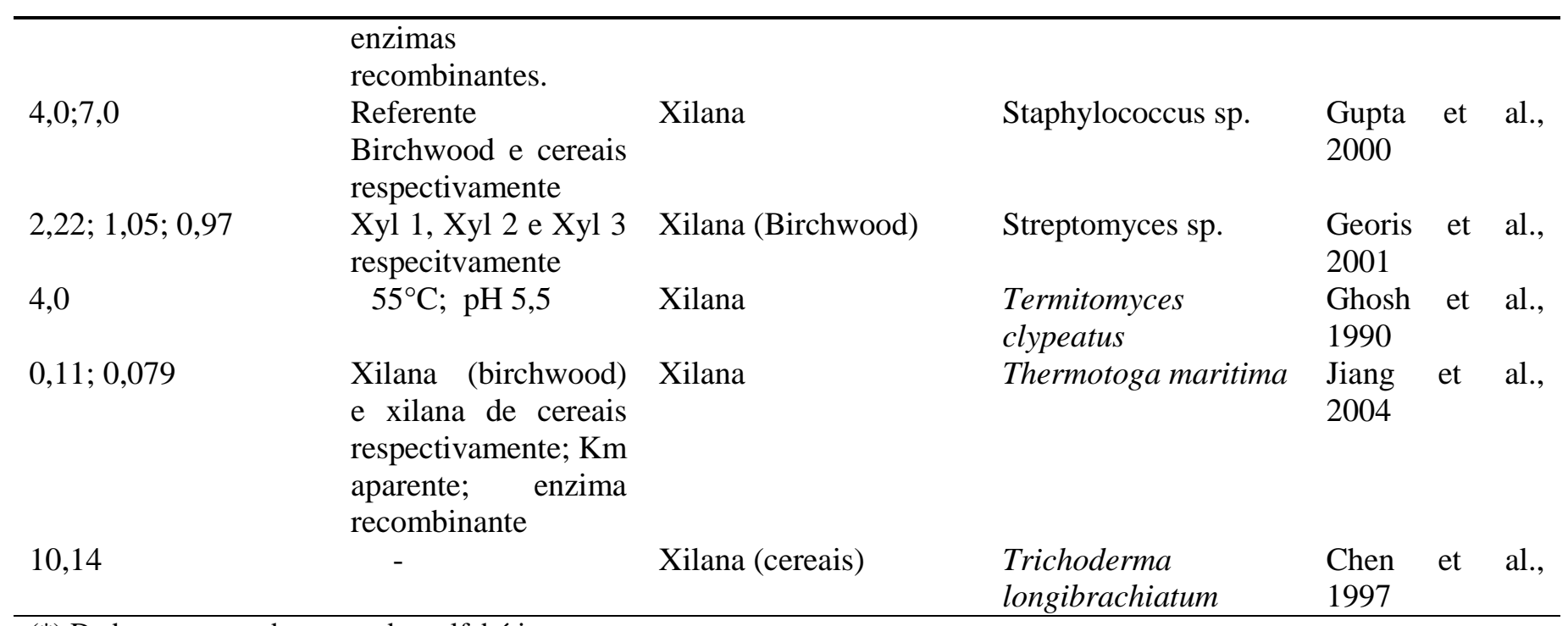

(*) Dados apresentados em ordem alfabética

\section{Purificação e aplicação biotecnológica das xilanases}

As xilanases são produzidas principalmente por bactérias e fungos e hidrolisam, em grande parte dos trabalhos revisados, a xilana. A purificação é uma etapa importante que precede a aplicação biotecnológica das xilanases, técnicas de purificação são utilizadas na maioria dos trabalhos (Tabela 1) e é essencial para obtenção de enzimas puras, específicas e sem perda de atividade enzimática (Zuniga et al., 2003). A purificação enzimática pode ser baseada na alteração da solubilidade. Tal mecanismo baseia-se principalmente na precipitação por sais. Sapre et al. (2005) realizaram a purificação e caracterização da xilanase termoalcalofílica proveniente de bactérias do gênero bacillus; esta xilanase foi purificada através da adição do sulfato de amônio. Mesmo procedimento foi utilizado por Decelle et al. (2004), com a purificação de endo-1,4- $\beta$ xilanases da Phanerochaete chrysosporium.

A purificação também pode ser baseada na carga inerente da enzima. A cromatografia de trocaiônica permite a migração diferencial das enzimas numa mistura. Kolenová et al. (2005) utilizaram a cromatografia de troca-iônica para a purificação de endo-1,4- $\beta$-xilanases de Schizophyllum commune. Outra técnica cromatográfica muito utilizada para a purificação das xilanases é a cromatografia em gel ou filtração a gel; esta análise cromatográfica baseia-se no tamanho molecular da enzima. Geralmente é usada após a realização de uma separação baseada na carga da enzima (Kolenová et al., 2005; Sapre et al., 2005).
O conhecimento dos parâmetros cinéticos é de extrema importância para a modelagem de um processo bioquímico. Através do estudo desses parâmetros pode-se inferir, por exemplo, a velocidade de utilização de substratos e de crescimento da biomassa. A caracterização da endo - 1,4 - $\beta$ - Xilanase do Penicillium citrinum. e a atividade enzimática ótima a $\mathrm{pH} 5,0 ; 55^{\circ} \mathrm{C}$, usando xilana como substrato, foram verificadas tendo-se conhecimentos prévios dos parâmetros cinéticos da enzima (Tanaka et al., 2005). Dados referentes à atividade enzimática ótima são levados em consideração na sua aplicação em um processo industrial.

A aplicação biotecnológica das xilanases tem aumentado nas últimas décadas. Grande destaque tem sido dado para as xilanases termoestáveis. A termoestabilidade é essencial para certas aplicações industriais que se desenvolvem em temperaturas elevadas ( $\mathrm{Wu}$ et al., 2008). Recentemente, xilanases termoestáveis têm sido usadas na indústria de panificação. Jiang et al. (2008), estudou o efeito da xilanase termoestável, da Thermotoga marítima na melhora da qualidade no congelamento parcial de pães assados. A xilanase aumentou a maciez e o volume do pão, melhorou a firmeza da migalha e diminuiu a recristalização da amilopectina do pão assado parcialmente congelado (Jiang et al., 2008). Sendo assim, as xilanases termoestáveis se colocam como boa estratégia para a aditivação de produtos panificados nas etapas de produção e armazenamento (Haros et al., 2002; Jiang et al., 2008;). Xilanases termoestáveis podem ser utilizadas também na produção de papel. A 
verificação da aplicação industrial da xilanase termoestável, obtida da Thermotoga marítima, no pré-branqueamento da polpa Kraft (Jiang et al., 2004), onde este procedimento é essencial para a obtenção de um papel de boa qualidade (Bae et al., 2008).

\section{RESUMO}

As endo $\beta$ 1,4 xilanases são enzimas extracelulares que fazem a hidrólise de substratos que possuem ligações do tipo $\beta$ 1,4. A xilana é o principal representante dentre os substratos susceptíveis ao ataque hidrolítico das xilanases. Encontra vasta aplicação em diferentes setores da economia. O objetivo do presente trabalho foi revisar a literatura publicada sobre as principais metodologias utilizadas para se trabalhar com estas enzimas, bem como reunir alguns parâmetros cinéticos. As metodologias revisadas estão centralizadas principalmente no processo de purificação, haja vista que é uma etapa essencial para otimização da sua atividade enzimática e conseguinte aplicação industrial. Destacam-se as técnicas que utilizam a precipitação por sais e metodologias refinadas como a cromatografia e suas variações. Tem ganhado destaque, em pesquisas acadêmicas, os estudos de planejamentos fatoriais e imobilização enzimática. Tais metodologias buscam respectivamente, dentre outras coisas, condições otimizadas de produção e reciclagem enzimática.

Palavras-chave: Atividade enzimática, técnicas de purificação, imobilização de enzimas, xilanas, termoestabilidade

\section{REFERÊNCIAS}

Bae, H. J.; Kim, H. J.; Kim, Y. S. (2008), Production of a recombinant xylanase in plants and its potential for pulp biobleaching applications. Bioresource Technology, 99, 35133519.

Bakalova, N. G.; Petrova, S. D.; Atev, A. P.; Bhat, M. K.; Kolev, D. N. (2002), Biochemical and catalytic properties of endo-1,4-beta-xylanases from Thermomyces lanuginosus (wild and mutant strains). Biotechnology Letters, 24, 1167-1172.

Bataillon, M.; Nunes Cardinali, A. P.; Castillon, N.; Duchiron, F. (2000), Purification and characterization of a moderately thermostable xylanase from Bacillus sp. strain SPS-0. Enzyme and Microbial Technology, 26, 187-192.

Cardoso, O. A. V. and Ferreira Filho, E. X. (2003), Purification and characterization of a novel cellulase-free xylanase from Acrophialophora nainiana. FEMS Microbiology Letters, 223, 309314.

Carmona, E. C.; Fialho, M. B.; Buchgnani, E. B.; Coelho, G. D.; Brocheto-Braga, M. R.; Jorge, J. A. (2005), Production, purification and characterization of a minor form of xylanase from Aspergillus versicolor. Process Biochemistry, 40, 359-364.

Cepeljnik, T.; Krizaj, I.; Marinsek-Logar, R. (2004), Isolation and characterization of the Pseudobutyrivibrio xylanivorans Mz5T xylanase XynT - the first family 11 endoxylanase from rumen Butyrivibrio-related bacteria. Enzyme and Microbial Technology, 34, 219-227.

Chen, C.; Chen, J-L.; Lin, T-Y. (1997), Purification and characterization of a xylanase from Trichoderma longibrachiatum for xylooligosaccharide production. Enzyme and Microbial Technology, 21, 91-96.

Collins, T.; Meuwis, M. A.; Stals, I.; Claeyssens, M.; Feller, G.; Gerday, C. (2002), A Novel Family 8 Xylanase, Functional and Physicochemical Characterization. The Journal of Biological Chemistry, 277, 35133-35139.

Damaso, M. C. T.; Almeida, M. S.; Kurtenbach, E.; Martins, O. B.; Pereira-Jr. N.; Andrade, C. M. M. C.; Albano, R. M. (2003), Optimized expression of a thermostable xylanase from thermomyces lanuginosus in Pichia pastoris. Applied and environmental microbiology, 69, 6064-6072.

Debeire, P.; Priem, B.; Strecker, G.; Vignon, M. (1990), Purification and properties of an endo-1,4xylanase excreted by a hydrolytic thermophilic anaerobe, Clostridium thermolacticum: A proposal for its action mechanism on larchwood 4-0methylglucuronoxylan. European Journal of Biochemistry, 187, 573-580.

Decelle, B.; Tsang, A.; Storms, R. K. (2004), Cloning, functional expression and characterization of three Phanerochaete chrysosporium endo-1,4- $b$-xylanases. Current Genetics, 46, 166-175.

Fernández-Espinar, M.; Piñaga, F.; Graaff, L. de; Visser, J.; Ramón, D.,Vallés, S. (1994), 
Purification, characterization and regulation of the synthesis of an Aspergillus nidulans acidic xylanase. Applied Microbiology and Biotechnology, 42, 1994.

George, S. P.; Ahmad, Rao, M. B. (2001), Involvement of a Lysine Residue in the Active Site of a Thermostable Xylanase from Thermomonospora sp. Biochemical and Biophysical Research Communications, 282, 4854.

Georis, J.; Giannottaa, F.; De Buyl, E.; Granier, B.; Frèrea, J-M. (2000), Purification and properties of three endo-b-1,4-xylanases produced by Streptomyces sp. strain S38 which differ in their ability to enhance the bleaching of kraft pulps . Enzyme and Microbial Technology, 26, 178-186.

Ghosh, A. K.; Banerjee, P. C.; Sengupta, S. (1980), Purification and properties of xylan hydrolase from mushroom Termitomyces clypeatus. Biochimica Biophysica Acta, 612, 143152.

Gupta, S.; Bhushan, B.; Hoondal, G. S. (2000), Isolation, purification and characterization of xylanase from Staphylococcus sp. SG-13 and its application in biobleaching of kraft pulp. Journal of Applied Microbiology, 88, 325-334.

Haros, M.; Rosell, C. M.; Benedito, C. (2002), Effect of different carbohydrases on fresh bread texture and bread staling. European Food Research and Technology, 215, 425-430.

Heck, J. X.; Soares, L. H. B.; Hertz, P. F.; Ayub, M. A Z. (2006), Purification and properties of a xylanase produced by Bacillus circulans BL53 on solid-state cultivation. Biochemical Engineering Journal, 32, 179-184.

Jänis, J.; Pulkkinen, P.; Rouvinen, J.; Vainiotalo, P. (2007), Determination of steady-state kinetic parameters for a xylanase-catalyzed hydrolysis of neutral underivatized xylooligosaccharides by mass spectrometry. Analytical Biochemistry, 365, 165-173.

Jiang, Z. Q.; Deng, W.; Zhu, Y. P.; Li, L. T.; Sheng, Y.J.; Hayashi, K. (2004), The recombinant xylanase B of Thermotoga maritima is highly xylan specific and produces exclusively xylobiose from xylans, a unique character for industrial applications. Journal of Molecular Catalysis B: Enzymatic, 27, 207-213.

Jiang, Z.; Bail, A. L.; Wu, A. (2008), Effect of the thermostable xylanase B (XynB) from Thermotoga maritima on the quality of frozen partially baked bread. Journal of Cereal Science, 47, 172-179.

Kalogeris, E.; Christakopoulos, P.; Vrsanská. M.; Kekos, D.; Macris, B. J. (2001), Catalytic properties of the endoxylanase I from Thermoascus aurantiacus. Journal of Molecular Catalysis B: Enzymatic, 11, 491-501.

Kaneko, S.; Kuno, A.; Muramatsu, M.; Iwamatsu, S.; Kusakabe, I.; Hayashi, K. (2000), Purification and characterization of a family G/11 betaxylanase from Streptomyces olivaceoviridis E-86. Bioscience, Biotechnology, and Biochemistry, 634, 447-451.

Katapodis, P.; Vrsanská, M.; Kekos, D.; Nerinckx, W.; Biely, P.; Claeyssens, M.; Macris, B. J.; Christakopoulos, P. (2003), Biochemical and catalytic properties of an endoxylanase purified from the culture filtrate of Sporotrichum thermophile. Carbohydrate Research, 338, 18811890.

Khanna, S. and Gauri. (1993), Regulation, purification, and properties of xylanase from Cellulomonas fimi. Enzyme and Microbial Technology, 15, 990-995.

Khasin, A.; Alchanati, I.; Shoham, Y. (1993), Purification and Characterization of a Thermostable Xylanase from Bacillus stearothermophilus T-6. Applied and environmental microbiology, 59, 1725-1730.

Kolenová, K.; Vrsanská, M.; Biely, P. (2005), Purification and characterization of two minor endo- $\beta-1,4-x y l a n a s e s$ of Schizophyllum commune. Enzyme and Microbial Technology, 36, 903-910.

Kolenová, K.; Vrsanská, M.; Biely, P. (2005), Purification and characterization of two minor endo- $\beta-1,4-x y l a n a s e s o f$ Schizophyllum commune. Enzyme and Microbial Technology, 36, 903-910.

Krisana, A.; Rutchadaporn, S.; Jarupan, G.; Lily, G.; Sutipa, T.; Kanyawim, K. (2005), Endo-1,4- $\beta$ - 
xylanase B from Aspergillus cf. niger BCC14405 Isolated in Thailand: Purification, Characterization and Gene Isolation. Journal of Biochemistry and Molecular Biology, 38, 17-23.

Lama, L.; Calandrelli, V.; Gambacorta, A.; Nicolaus, B. (2004), Purification and characterization of thermostable xylanase and $\beta$ xylosidase by the thermophilic bacterium Bacillus thermantarc. Research in Microbiology, 155, 283289.

Levasseur, A.; Asther, M.; Record, E. (2005), Overproduction and characterization of xylanase B from Aspergillus niger. Canadian Journal of Microbiology, 51, 177-183.

Li, Y.; Cui, F.; Liu, Z.; Xu, Y.; Zhao, H. (2007), Improvement of xylanase production by Penicillium oxalicum ZH-30 using response surface methodology. Enzyme and Microbial Technology, 40, 1381-1388.

Mansour, F. A.; Shereif, A. A.; Nour El-Dein, M. M.; Bou-Dodara, M. I.; Ball, A. S. (2003), Purification and characterization of xylanase from a thermophilic Streptomyces sp. K37. Acta Microbiologica Polonica, 52, 159-172.

Martínez-Trujillo, A.; Pérez-Avalos, O.; PonceNoyola, T. (2003), Enzymatic properties of a purified xylanase from mutant PN-120 of Cellulomonas flavigena. Enzyme and Microbial Technology, 32, 401-406.

Ramos, C.; Morais, H.; Forgacs, E.; Cserhati, T.; Matos, N.; Oliveira, J. S. (2000), Biochemical characterization of xylanases of four strains of Lentinus edodes. Environmental Research Letters, 9, 219-227.

Rogalski J, Oleszek M, Tokarzewska-Zadora J. (2001), Purification and characterization of two endo-1,4-beta-xylanases and a 3-xylosidase from phlebia radiata. Acta Microbiologica Polonica, 50, 117-128.

Saha, B. C. (2002), Production, purification and properties of xylanase from a newly isolated Fusarium proliferatum. Process Biochemistry. 37, 1279-1284.
Salles, B. C.; Cunha, R. B.; Fontes , W.; Sousa, M. V.; Filho, E. X. F. (2000), Short communication Purification and characterization of a new xylanase from Acrophialophora nainiana. Journal of Biotechnology, 81, 199-204.

Sandrima, V. C.; Rizzatti, A. C. S.; Terenzi, H. F.; Jorgeb, J. A.; Milagres, A. M. F.; Polizeli, M. L. T. M. (2005), Purification and biochemical characterization of two xylanases produced by Aspergillus caespitosus and their potential for kraft pulp bleaching. Process Biochemistry, 40, 1823-1828.

Sapre, M. P.; Jha, H.; Patil, M. B. (2005), Purification and characterization of a thermoalkalophilic xylanase from Bacillus sp. World Journal of Microbiology \& Biotechnology, 21, 649-654.

Saraswat, V. and Bisaria, V. S. (2000), Purification and characterization and substrates specificities from xylanases isoenziymes from Melanocarpus albomyces IIS 68. Bioscience Biotechnology and Biochemistry, 64, 1173-1180.

Sunna, A.; Gibbs, M. D.; Bergquistm P. L. (2000), A novel thermostable multidomain 1,4- $\beta$-xylanase from 'Caldibacillus cellulovorans' and effect of its xylan-binding domain on enzyme activity. Microbiology, 146, 2947-2955.

Takahashi, H.; Nakai, R.; Nakamura, S. (2000), Purification and partial characterization of a basic Xylanase Produced by Thermoalkaliphilic Bacillus sp. Strain TAR-1. Bioscience, Biotechnology, and Biochemistry, 64, 887-890.

Tanaka, H.; Nakamura, T.; Hayashi, S.; Ohta, K. (2005), Purification and Properties of an Extracellular Endo-1,4- $\beta$-Xylanase from Penicillium citrinum and Characterization of the Encoding Gene. Journal of Bioscience and Bioengeenering, 100, 623-630.

Turkiewicz, M.; Kalinowska, H.; Zielinska, M.; Bielecki, S. (2000), Purification and characterization of two endo-1,4- xylanases from Antarctic krill, Euphausia superba Dana. Comparative Physiology and Biochemistry, 27, 325-335. 
Wu, H.; Pei, J.; Wu, G.; Shao, W. (2008), Overexpression of GH10 endoxylanase XynB from Thermotoga maritima in Escherichia coli by a novel vector with potential for industrial application. Enzyme and Microbial Technology, 42, 230-234.
Zuniga, A. D. G.; Pereira, J. A. M.; Coimbra, J. S. R.; Minim, L. A.; Rojas, E. E. G. (2003), Técnicas usadas no processo de purificação de biomoléculas. Boletim do Ceppa, 21, 61-82. 